\title{
Modelling the Dispersion of Non-Conservative Radionuclides in Tidal Waters - Part 1: Conceptual and Mathematical Model
}

\author{
R. Periáñez, J. M. Abril \\ Departamento Física Aplicada, E U Ingeniería Técnica Agrícola, Universidad de Sevilla, \\ Ctra. Utrera km. 1, 41014 Sevilla, Spain \\ $\&$

\section{García-León} \\ Departamento Física Atómica, Molecular y Nuclear, Universidad de Sevilla, Apdo. 1065, \\ 41080 Sevilla, Spain
}

(Received 3 April 1995; accepted 3 July 1995)

ABSTRACT

A $2 D$ four-phase model to study the dispersion of non-conservative radionuclides in tidal waters, in conditions of disequilibrium for ionic exchanges, has been developed. At disequilibrium conditions, ionic exchanges cannot be formulated using distribution coefficients $\mathrm{k}_{d}$. Thus, kinetic transfer coefficients have been used. The model includes ionic exchanges among water and the solid phases (suspended matter and two grain size fractions of sediments), the deposition and resuspension of suspended matter and advective plus diffusive transport. In the second part of this work, which is presented in a separate paper, the model is applied to simulate ${ }^{226} \mathrm{Ra}$ dispersion, discharged from a fertilizer processing plant, in an estuarine system in the south-west of Spain.

\section{INTRODUCTION}

The use of mathematical models to study the dispersion of radionuclides in aquatic systems has increased during the last few years. There are 
some good models which successfully describe the dispersion of dissolved radionuclides in marine environments (see, for instance, Prandle, 1984). These models allow the study of the dispersion of conservative radionuclides. However, every substance has some affinity to the suspended matter in the water column and to the bottom sediments. Thus, ionic exchanges among the phases (water, suspended matter, and sediments) must be taken into account in order to improve the model predictions when studying the dispersion of radionuclides in aquatic environments.

The first models were annually averaged box models in which ionic exchanges among the above mentioned three phases were described by the distribution coefficient $\left(k_{\mathrm{d}}\right)$. The water circulation was obtained by fitting the predictions of the model to observations when the dispersion of an 'almost' conservative radionuclide was simulated $\left({ }^{137} \mathrm{Cs}\right.$ ) (Kershaw et al., 1988; Howorth \& Eggleton, 1988).

The model of Abril and García-León $(1993 a, b)$ included ionic exchanges among four phases (water, suspended, matter, and two fractions of sediments) and the water circulation was calibrated by using salinity as a conservative tracer. The model worked with residual water circulation with a time step of $1.75 \mathrm{~h}$, thus it was assumed that ionic exchanges had reached the equilibrium inside each time step and that they could be described by $k_{\mathrm{d}}$.

Nevertheless, when studying the dispersion of non-conservative radionuclides in small coastal regions or estuaries, these models cannot be used. The reason is related to the fact that high spatial and temporal resolution is required. Thus, ionic exchanges do not reach equilibrium inside each time step and then the $k_{\mathrm{d}}$ (which are defined at equilibrium conditions) cannot be used.

High temporal resolution is needed because of its relationship to the spatial resolution. As can be seen in, for instance, Prandle (1974), spatial and temporal resolutions must satisfy a stability condition (the CourantFriederich-Lewy criterion). Moreover, in environments like estuaries the influence of tides in the dispersion of any contaminant is significant, since they produce a constant movement of waters and to study the effect of tides, high temporal resolution is required.

In this paper, a model to simulate non-conservative radionuclide dispersion in tidal waters (under non-equilibrium conditions for ionic exchanges) is presented. For each time step, the hydrodynamic equations are solved to obtain the instantaneous water state. Then the suspended matter dispersion equation, which contains the deposition and resuspension terms, both depending on the water state, is solved. Finally, ionic exchanges of radionuclides among four phases (water, suspended matter, and two grain frac- 
tions of sediments) are included by using transfer coefficients instead of the $k_{\mathrm{d}}$, because they do not require an equilibrium state for the exchanges.

The interest in studying radionuclide dispersion in coastal waters and estuaries is related to the fact that important human and industrial concentrations are often located beside those environments. The last may produce, through waste disposal, a radiological impact on the population.

In the second part of this work (Periáñez et al., 1996) the model is applied to study ${ }^{226} \mathrm{Ra}$ dispersion in an estuary system in the south-west of Spain, in which a phosphate fertilizer plant releases its waste. Thus, high ${ }^{226} \mathrm{Ra}$ concentrations have been measured in waters (Periáñez \& GarcíaLeón, 1993), suspended matter (Periáñez et al., 1994a) and sediments (Martínez-Aguirre et al., 1994).

In the next section we present the conceptual model. The hydrodynamic and suspended malter dynamic is briefly presented in Section 3 and the equations for the four phases in Section 4. In Section 5 the computational scheme is summarised.

\section{CONCEPTUAL MODEL}

The system under study is divided into a number of grid cells. Four phases are present inside each cell, which are water, suspended matter and two grain size fractions of sediments.

In Fig. 1 a grid cell is presented. Inside it, the processes included in the model are shown. Radionuclides can be dissolved and associated with suspended matter. As tides produce a continuous movement of water, radionuclides in both phases will be transported from one cell to another by advection and diffusion.

As is usual, we will consider that only particles with a diameter $\phi<62.5 \mu \mathrm{m}$ will be present in the water column as suspended matter. Larger particles will quickly sink to the bottom (Gurbutt et al., 1987). In sediments, we will consider two grain size fractions: particles with $\phi<62.5 \mu \mathrm{m}$ (small grain fraction) and particles with $\phi>62.5 \mu \mathrm{m}$ (large grain fraction). Only the small grain size fraction of sediments can be resuspended into the water column and incorporated into suspended matter. On the other hand, when suspended matter is deposited on the estuary bed, it will be incorporated in the small grain size fraction of the sediment. Thus, the deposition and resuspension processes will produce an exchange of radionuclides between suspended matter and the small grain size fraction of sediments.

The dissolved phase is in contact with the other three phases, thus ionic exchange takes place among them. The dissolved phase may penetrate 


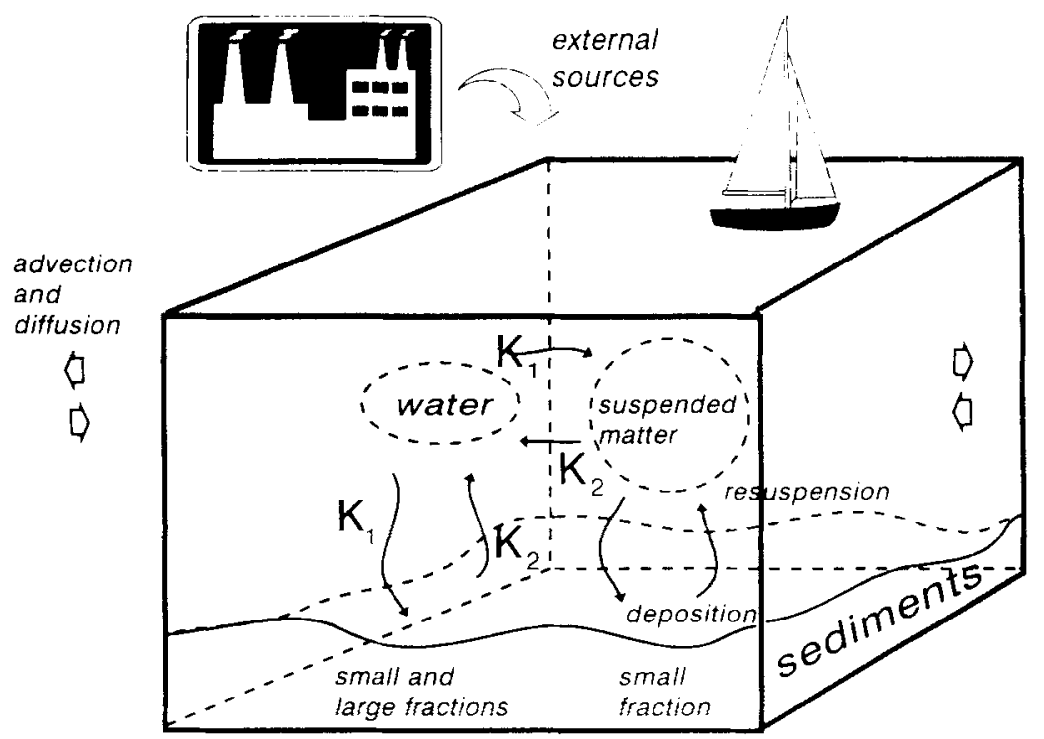

Fig. 1. Grid cell in which the radionuclides transfer processes among the four phases are presented.

inside the sediment to a mean depth $L$, due to the sediment porosity. It is necessary to know the proportion of sediments of small and large grain size fractions inside this effective thickness $L$. This information is described by the parameter $f$, which gives the dry weight fraction of small particles in the sediment. But not all the sediments are in contact with the water, that is, not all the sediment mass of each fraction will participate in the ionic exchanges. This is due to geometrical reasons. Thus, two geometrical accessibility factors (one for each sediment fraction) are introduced. They will be estimated from a calibration exercise. Finally, external sources of radionuclides (in dissolved and suspended phases) may exist in each grid cell.

The formulation of the ionic exchanges is presented in what follows. Consider a two-phase closed system. Let activities $A_{1}$ and $A_{2}$ be present in each one of them. The rate of flow of radionuclides (or any other substance) between phases is described by transfer coefficients. Thus, radionuclides will leave the phase at a rate which is proportional to the activity present in the phase, being the proportional factor the transfer coefficient. The equations for the time evolution of the activity in each phase are (see, for instance, Robertson, 1983):

$$
\frac{\partial A_{1}}{\partial t}=-k_{1} A_{1}+k_{2} A_{2}
$$




$$
\frac{\partial A_{2}}{\partial t}=k_{1} A_{1}-k_{2} A_{2}
$$

$k_{1}$ and $k_{2}$ being the transfer coefficients which link both phases.

In a similar way, the transfer from water to the solid phases (suspended matter and the two fractions of sediments) is governed by a transfer coefficient $k_{1}$ and the inverse process by a coefficient $k_{2}$, as it is shown in Fig. 1.

The process of transfer of radionuclides from water to the solid phases is a surface phenomenon, that is, it happens at the surface of particles. Consequently, it will depend on the amount of particles (suspended matter and sediments), or more explicitly, on the surface of particles per water volume unit in the grid cell. In what follows, we call such a ratio the exchange surface. The transfer to the solid phase will increase when the exchange surface in water increases since radionuclides, which are moving randomly through the water, will have a larger probability of colliding with particles of suspended matter. The transfer coefficient $k_{1}$ will be proportional to the exchange surface:

$$
k_{1}=\chi_{1} S_{\mathrm{s}}
$$

where $S_{\mathrm{s}}$ is the exchange surface for suspended matter. This is true if the surface density of charge in suspended matter particles is constant, since it governs ionic exchanges. As the dimensions of $k_{1}$ are $[\mathrm{T}]^{-1}$ and $S_{\mathrm{s}}$ is surface per volume unit (dimensions $[\mathrm{L}]^{-1}$ ), $\chi_{1}$ has dimensions of $[\mathrm{L}][\mathrm{T}]^{-1}$, which is a velocity. This coefficient is then related to the molecular velocity of the dissolved radionuclides, which at the same time is related to the temperature of the water. As a first approach, a step function, ranging from 0 to $60 \mu \mathrm{m}$, has been assumed for the grain size distribution of suspended matter particles. Indeed, the mean radius for this distribution will not be very different from that obtained by using the real grain size spectrum. The exchange surface will be:

$$
S_{\mathrm{s}}=\frac{m}{\rho \frac{4}{3} \pi R^{3}} 4 \pi R^{2}=\frac{3 m}{\rho R}
$$

where $m$ is the suspended matter concentration, $\rho$ the density of particles in suspension and $R$ is the mean radius of such particles. As will be seen (Periáñez et al., 1996), it is possible to obtain $\chi_{1}$ and $k_{2}$ from laboratory experiments.

Some of the activity in water will be incorporated in both fractions of sediments. The small grain size fraction sediment mass present in a grid cell of surface $\mathrm{d} x \mathrm{~d} y$ is:

$$
M_{\mathrm{f}}=\mathrm{d} x \mathrm{~d} y L \rho_{\mathrm{m}} f \psi
$$


where $\rho_{\mathrm{m}}$ is the bulk density of sediment, $L$ the effective thickness of the sediment and $\psi$ is the geometrical factor. It is introduced to take into account only the mass which is accessible to water. If we divide eqn (5) by the total water volume into the grid cell $(\mathrm{d} x \mathrm{~d} x H$ if $H$ is the water column height) then we will have the concentration of small grain size sediments in the grid cell. By applying eqn (4), the exchange surface for the small grain size fraction of the sediment is:

$$
S_{\mathrm{sf}}=\frac{3 L f \psi}{R H}
$$

where the mean radius of particles is supposed to be the same for suspended matter and for the small grain size fraction of sediments.

In a similar way, the large grain size fraction mass into the grid cell is:

$$
M_{1}=\mathrm{d} x \mathrm{~d} y L \rho_{\mathrm{m}}(1-f) \psi^{\prime}
$$

$\psi^{\prime}$ being the geometrical accessibility factor for the large fraction of the sediment. Now, the exchange surface will be:

$$
S_{\mathrm{lf}}=\frac{3 L(1-f) \psi^{\prime}}{R_{\mathrm{l}} H}
$$

if $R_{1}$ is the mean radius for the large grain size particles. The total exchange surface is $S=S_{\mathrm{s}}+S_{\mathrm{sf}}+S_{\mathrm{lf}}$ and the transfer coefficient is written as:

$$
k_{1}=\chi_{1}\left(\frac{3 m}{\rho R}+\frac{3 L f \psi}{R H}+\frac{3 L(1-f) \psi^{\prime}}{R_{1} H}\right)
$$

It is interesting to note that $k_{1}$ is proportional to the suspended matter concentration. Indeed, some laboratory experiments (Benes et al., 1992; Benes \& Cernik, 1992) have shown that a direct relation exists among them. Equation (9) is the analytical form of such a relation.

This is the conceptual model for transfer among phases. In the following sections we will present the equations which will describe the considered processes.

\section{HYDRODYNAMICS AND SUSPENDED MATTER DYNAMICS}

The water circulation is obtained from the hydrodynamic equations, the solutions of which give the instantaneous water state (water displacement from the mean level due to tides and water velocity) for each grid cell. These equations include the advective terms, Coriolis term, bed friction, response to wind stress and response to changes in atmospheric pressure. The equations can be seen in detail in Periáñez et al. (1994b) and Pugh (1987). They are summarized in the Appendix. 
As we have a set of partial differential equations with coefficients changing in time and space, there is no analytical solution. Thus, a temporal and spatial discretisation of the equations is carried out and a finite differences scheme is adopted to solve the equations, using forward differences in time and centred differences in space. The spatial and temporal resolutions of the model (grid cells size and time step) are selected so as to satisfy a stability condition and to minimise numerical dispersion (Periáñez et al., 1994b).

A calibration was carried out, which consists of selecting the best value for the bed friction coefficient and the boundary conditions in such a way that the behaviour of water in conditions of neap and medium tides is reproduced by the model. Details of the model and its calibration can be seen in Periáñez et al. $(1994 b, c)$.

Once the hydrodynamic model is calibrated, the advective-diffusive dispersion equation (see Appendix), which governs the dispersion of a conservative substance, can be included. This equation must be calibrated as well. This calibration consists of selecting good values for the diffusion coefficients and good boundary conditions. It has been performed by applying the model to study ${ }^{226} \mathrm{Ra}$ dispersion. As a first approach, ${ }^{226} \mathrm{Ra}$ was considered as a conservative radionuclide. When calibrating both the hydrodynamics and the dispersion equation, appropriate initial conditions must also be given. Details can be found in Periáñez et al. $(1994 b, c, d)$.

The dispersion equation governs the horizontal movement of suspended matter, the vertical movement is governed by the resuspension and deposition terms. They have been formulated using critical deposition and resuspension velocities in such a way that there is deposition only if the water velocity is smaller than the critical deposition velocity. For larger values of the water velocity the deposition is hindered by water turbulence. On the other hand, there is resuspension only if the water velocity is larger than the critical resuspension velocity, otherwise there will not be enough energy to lift up particles from the sediment. The equations and their application to study the suspended matter distribution and sedimentology in an estuarine system in south-west Spain can be seen in Periáñez et al. (in press). The mathematical form of the deposition and resuspension terms can be seen in the Appendix.

\section{EQUATIONS FOR THE TRANSFERS AMONG PHASES}

\subsection{The dissolved phase}

The equation which gives the time evolution of the radionuclide concentration in the dissolved phase $\left(C_{\mathrm{d}}\right.$, in $\left.\mathrm{Bq} \mathrm{m}^{-3}\right)$ in each grid cell is: 


$$
\frac{\partial C_{\mathrm{d}}}{\partial t}=-k_{1} C_{\mathrm{d}} \frac{H}{H^{*}}+k_{2} C_{\mathrm{s}} m \frac{H}{H^{*}}+k_{2}\left(\operatorname{sed}_{\mathrm{s}}+\operatorname{sed}_{1}\right)+(a d v+d i f)
$$

The time derivative is interpreted as in a forward finite difference scheme. The first term is the transfer of radionuclides from water to suspended matter and both fractions of sediments. Thus, $k_{1}$ is given by eqn (9). The second term is the transfer from suspended matter to water $\left(C_{\mathrm{s}}\right.$ is the radionuclide concentration in suspended matter in $\mathrm{Bqg}^{-1}$ ) and the following terms are the transfer of radionuclides from the small and the large grain fractions of sediments to water. $a d v+$ dif means advective plus diffusive transport of dissolved radionuclides from one grid cell to another. Advective and diffusive transport is done by solving the dispersion equation (eqn (A5) in the Appendix) previously written in finite differences (see Periáñez et al., $1994 b$ for details). The * means that the corresponding water column height must be computed in the new time step. The external source of radionuclides should be added to this equation if it exists.

Terms $H / H^{*}$ appear because transfer coefficients are defined for total activities in each phase, while $C_{\mathrm{d}}$ and $C_{\mathrm{s}}$ are specific activities.

The activity which can be transferred from the small grain fraction of the sediment to the water in the grid cell is:

$$
a_{\mathrm{s}} L \mathrm{~d} x \mathrm{~d} y \rho_{\mathrm{m}} f \psi \times 10^{3}
$$

if $a_{\mathrm{s}}$ is the specific activity of that grain size fraction $\left(\mathrm{Bq} \mathrm{g}^{-1}\right)$ and the density is given in $\mathrm{kg} \mathrm{m}^{-3}$. Dividing by the water volume in the grid cell we have that the transfer of radionuclides from the small grain size fraction of the sediment to the water may be written as:

$$
\operatorname{sed}_{\mathrm{s}}=\frac{a_{\mathrm{s}} L \rho_{\mathrm{m}} f \psi}{H^{*}} \times 10^{3}
$$

And similarly, for the large grain size fraction of the sediment:

$$
\operatorname{sed}_{1}=\frac{a_{1} L \rho_{\mathrm{m}}(1-f) \psi^{\prime}}{H^{*}} \times 10^{3}
$$

where $a_{1}$ is the specific activity in the large grain fraction of the sediment.

\subsection{Suspended matter}

The equation for the time evolution of specific activity in suspended matter (in $\mathrm{Bq} \mathrm{g}^{-1}$ ) is:

$$
\frac{\partial C_{\mathrm{s}}}{\partial t}=k_{1} \frac{C_{\mathrm{d}} H}{m^{*} H^{*}}-k_{2} C_{\mathrm{s}} \frac{m H}{m^{*} H^{*}}+(r e s-d e p)+(a d v+d i f)
$$


where again $a d v+$ dif is advective plus diffusive transport of radionuclides in suspended matter and $m^{*}$ is the suspended matter concentration in the new time step. The first term is transfer from water to suspended matter, thus in this case (from eqn (4)) we have that:

$$
k_{1}=\chi_{1} \frac{3 m}{\rho R}
$$

The second term is the transfer of radionuclides from suspended matter to water. The transfers between the suspended matter and the small grain size fraction of sediments are governed by the resuspension and deposition processes. The formulation of these processes, from which the terms dep and res terms are obtained, can be seen in Periáñez et al. (in press).

The activity in $\mathrm{Bq}$ which is deposited on the bottom for each unit time is:

$$
\frac{v_{\mathrm{d}}}{H} m\left(1-\frac{|q|}{v_{\mathrm{cd}}}\right) C_{\mathrm{s}} \mathrm{d} x \mathrm{~d} y H
$$

where $v_{\mathrm{d}}$ is the mean deposition velocity, $q$ the water flux velocity and $v_{\mathrm{cd}}$ the critical deposition velocity. The suspended matter content in the new time step is $\mathrm{d} x \mathrm{~d} y H^{*} m^{*}$. The deposition term (in $\mathrm{Bq} \mathrm{g}^{-1} \mathrm{~s}^{-1}$ ) is then written as:

$$
d e p=\frac{v_{\mathrm{d}} C_{\mathrm{s}} m}{m^{*} H^{*}}\left(1-\frac{|q|}{v_{\mathrm{cd}}}\right)
$$

In a similar way, the activity in $\mathrm{Bq}$ which is incorporated in suspended matter from the small grain size fraction of sediments in the unit of time is:

$$
\frac{v_{r}}{L}\left(\frac{|q|}{v_{\mathrm{cr}}}-1\right) \mathrm{d} x \mathrm{~d} y L f \rho_{\mathrm{m}} a_{\Gamma}
$$

The resuspension term $\left(\mathrm{Bq} \mathrm{g}^{-1} \mathrm{~s}^{-1}\right)$ is then:

$$
r e s=\frac{v_{\mathrm{r}} f \rho_{\mathrm{m}} a_{\mathrm{f}}}{m^{*} H^{*}}\left(\frac{|q|}{v_{\mathrm{cr}}}-1\right) \times 10^{3}
$$

where $v_{\mathrm{r}}$ is the mean resuspension velocity, $v_{\mathrm{cr}}$ the critical resuspension velocity, $\rho_{\mathrm{m}}$ is given in $\mathrm{kg} \mathrm{m}^{-3}$ and $m$ in $\mathrm{mgl}^{-1}$.

As in the case of the dissolved phase, external sources of radionuclides in suspended matter should be added if they exist.

\subsection{The sediments}

The equations for the small and the large grain size fractions will be written separately. The first fraction will exchange radionuclides with water 
and suspended matter, while the second fraction will exchange only with water.

The equation for the time evolution of the small grain size fraction specific activity, $a_{\mathrm{f}}$, is:

$$
\frac{\partial a_{\mathrm{f}}}{\partial t}=k_{1} \frac{C_{\mathrm{d}} H}{\rho_{\mathrm{m}}} L f \times 10^{-3} \quad k_{2} a_{\mathrm{f}} \psi+(\text { dep }-r e s)
$$

where $a_{\mathrm{f}}$ is given in $\mathrm{Bqg}^{-1}$.

The first term is the transfer of radionuclides from the water to the small fraction of the sediment. Thus:

$$
k_{1}=\chi_{1} \frac{3 L f \psi}{R H}
$$

The second term is the transfer from the sediment to water. The deposition and resuspension terms, which take into account the transfer of radionuclides between the suspended matter and the small grain size fraction of the sediment, have been written in the following way:

$$
\begin{aligned}
& \text { dep }=\frac{v_{\mathrm{d}} C_{\mathrm{s}} m}{L \rho_{\mathrm{m}} f}\left(1-\frac{|q|}{v_{\mathrm{cd}}}\right) \times 10^{-3} \\
& \text { res }=\frac{v_{\mathrm{r}} a_{\mathrm{f}}}{L}\left(\frac{|q|}{v_{\mathrm{cr}}}-1\right)
\end{aligned}
$$

where dep and res are given in $\mathrm{Bq}^{-1} \mathrm{~s}^{-1}$.

The equation for the time evolution of large grain size fraction specific activity ( $\left.\mathrm{Bq}^{-1}\right)$ is:

$$
\frac{\partial a_{1}}{\partial t}=k_{1} \frac{C_{\mathrm{d}} H}{L \rho_{\mathrm{m}}(1-f)} \times 10^{-3}-k_{2} a_{1} \psi^{\prime}
$$

The last term represents the transfer from the sediment to water and the first one the transfer from water to the large grain size fraction of the sediment. Thus:

$$
k_{1}=\chi_{1} \frac{3 L(1-f) \psi^{\prime}}{R_{1} H}
$$

\section{$4.4 k_{\mathrm{d}}$ description}

The distribution coefficients are experimentally obtained as the specific activity in suspended matter divided by the specific activity in water. Let us consider a spherical particle of density $\rho$ and radius $r$. The ionic 

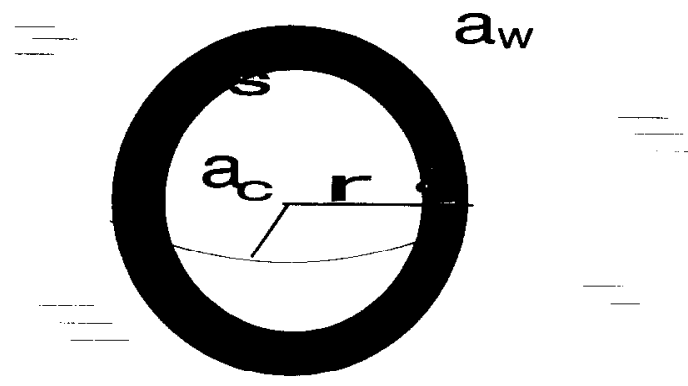

Fig. 2. Representation of a spherical particle with its central nucleus and surface layer.

exchanges take place only over a surface layer of thickness $\xi$ (see Fig. 2). $a_{\mathrm{w}}$ is the specific activity in filtered water, $a_{\mathrm{s}}$ is the specific activity in the surface layer of the particle and $a_{\mathrm{c}}$ is the specific activity in the central part of the particle. In the case of a naturally occurring radionuclide $a_{\mathrm{c}} \neq 0$ while for a man-made radionuclide $a_{\mathrm{c}}=0$.

Abril and Fraga (1995) have obtained that the distribution coefficient can be written as:

$$
k_{\mathrm{d}}=\frac{a_{\mathrm{s}}}{a_{\mathrm{w}}}\left(1-(1-\xi / r)^{3}\right)+\frac{a_{\mathrm{c}}}{a_{\mathrm{w}}}(1-\xi / r)^{3}
$$

This equation is true if $r>\xi$, since otherwise there will not be a central nucleus and the whole particle will participate in ionic exchanges.

When calculating $k_{\mathrm{d}}$ with the model, it must be taken into account that there will be an activity inside the particles $\left(a_{\mathrm{c}} \neq 0\right.$ for naturally occurring radionuclides). The model computes the first term of eqn (26) since the specific activity in suspended matter is obtained by dividing the surface activity by the total mass of the suspended particles. The second term of eqn (26) must be added to this calculation. $a_{\mathrm{c}}(1-\xi / r)^{3}$ is assumed to be constant all over the site where the model is applied since particle properties must not change from one point to another. It must be estimated from field information.

\section{COMPUTATIONAL SCHEME}

We have developed a code to solve the equations involved in our mathematical model. The code was implemented on a VAX-VMS computer.

The equations are computed in the following sequence for each time step:

(1) The hydrodynamic equations are solved so as to obtain the water elevation and velocity for each grid cell. 
(2) The advective-diffusive dispersion equation is evaluated for suspended matter, as well as the resuspension and deposition terms. The suspended matter concentrations and the sedimentation rate are then obtained for each grid cell. To solve these equations, the instantaneous water state must be known.

(3) Radionuclide dispersion. Equations (10), (14), (20) and (24) are solved in this sequence to obtain the concentrations of radionuclides in water, suspended matter and both fractions of sediments all along the grid.

(4) Sources. Extenal sources of suspended matter, dissolved radionuclides and radionuclides in particulate form are introduced into the grid cells in which these sources exist.

The output provides detailed information: time evolution of specific activities in each of the four phases in desired positions into the grid, activity concentration maps at desired instants of time and distribution coefficients $k_{\mathrm{d}}$ in desired positions and times. This information will be compared with experimental information.

The model was developed in different stages, in such a way that every new step includes the previously validated model and it is subjected to further validation. The introduction of the transfers among phases involves the inclusion of only a few new parameters: $L$, $R, R_{1}, \rho, \psi, \psi^{\prime}, \chi_{1}$ and $k_{2}$. Only the geometrical accessibility factors are obtained from calibration, the rest of the parameters are obtained from laboratory measurements or from current literature, as it will be seen in Periáñez et al. (1996). In Table 1, the different parameters involved in the model are presented, as well as the way in which they are obtained.

In the second part of this paper (Periáñez et al., 1996) the model is applied to the Odiel river, an estuary system at the south-west of Spain, in which a phosphate fertilizer processing plant releases its wastes.

\section{TABLE 1}

Parameters Involved in the Model, and the Source from which They are Obtained

\begin{tabular}{ll}
\hline Parameter & Source \\
\hline Bottom friction & Calibrated in hydrodynamic model \\
Diffusion coefficients & Calibrated from dissolved ${ }^{226} \mathrm{Ra}$ dispersion \\
$v_{\mathrm{r}}, v_{\mathrm{s}}, v_{\mathrm{cd}}, v_{\mathrm{cr}}$ & Studying suspended matter dynamics \\
$\chi_{1}, k_{2}$ & Laboratory experiments \\
$L, \rho, R$ & Literature data \\
$f, \rho_{\mathrm{m}}, a_{\mathrm{c}}, R_{1}$ & Field measurements \\
$\psi, \psi^{\prime}$ & Obtained from a calibration exercise \\
\hline
\end{tabular}




\section{ACKNOWLEDGEMENT}

This work was partially supported by ENRESA and EU Contract FI3PCT92-0035.

\section{REFERENCES}

Abril, J. M. \& Fraga, E. (1996). Some physical and chemical features of the variability of $k_{\mathrm{d}}$ distribution coefficients for radionuclides. $J$. Environ. Radioactivity, 30(3), 253-70.

Abril, J. M. \& García-León, M. (1993a). A 2D 4-Phases marine dispersion model for radionuclides. Part 1: Conceptual and computational model. J. Environ. Radioactivity, 20, 71-88.

Abril, J. M. \& García-León, M. (1993b). A 2D 4-Phases marine dispersion model for non-conservative radionuclides. Part 2: Two applications. J. Environ. Radioactivity, 20, 89-115.

Benes, P. \& Cernik, M. (1992). Kinetics of radionuclide interaction with suspended solids in modelling the migration of radionuclides in rivers. Effect of the concentration of solids and temperature. J. Radioanal. Nucl. Chem. Articles, 159, 187200.

Benes, P., Cernik, M. \& Lam-Ramos, P. (1992). Factors affecting interaction of radiocesium with freshwater solids. Contact time, concentration of solids and temperature. J. Radioanal. Nucl. Chem. Articles, 159, 201-18.

Gurbutt, P. A., Kershaw, P. J. \& Durance, J. A. (1987). Modelling the distribution of soluble and particle adsorbed radionuclides in the Irish Sea. In Radionuclides. A Tool for Oceanography, ed. J. C. Guary, P. Guegueniat \& R. J. Pentreath. Elsevier, Oxford, UK, pp. 395-490.

Howorth, J. M. \& Eggleton, A. E. J. (1988). Modelling the sea to land transfer of marine discharges from Sellafield. Validation against environmental measurements. In Reliability of Radioactive Transfer Models, ed. G. Desmet. Elsevier, Oxford, UK, pp. 261-7.

Kershaw, P. J., Pentreath, R. J., Gurbutt, P. A., Woodhead, D. S., Durance, J. A. \& Camplin, W. C. (1988). Modelling the behaviour of long-lived radionuclides in the Irish Sea. Comparison of model predictions with field observations. In Reliability of Radioactive Transfer Models, ed. G. Desmet. Elsevier, Oxford, UK, pp. 241-9.

Martínez-Aguirre, A., García-León, M. \& Ivanovich, M. (1994). The distribution of $\mathrm{U}$, Th and ${ }^{226} \mathrm{Ra}$ derived from the phosphate fertilizer industries on an estuarine system in southwest Spain. J. Environ. Radioactivity, 22, 15577.

Periáñez, R. \& García-León, M. (1993). Ra-isotopes around a phosphate fertilizer complex in an estuarine system at the southwest of Spain. J. Radioanal. Nucl. Chem. Articles, 172, 71-9.

Periáñez, R., García-León, M. \& Abril, J. M. (1994a). Radium isotopes in suspended matter in an estuarine system in the southwest of Spain. $J$. Radioanal. Nucl. Chem. Articles, 183, 395-407.

Periáñez, R., Abril, J. M. \& García-León, M. (1994b). A modelling study of 
${ }^{226} \mathrm{Ra}$ dispersion in an estuarine system in southwest Spain. J. Environ. Radioactivity, 24, 159-79.

Periáñez, R., Abril, J. M. \& Garcia-León, M. (1994c). Aplicación de modelos numéricos al estudio de sistemas portuarios: dinámica de las aguas, dispersión de contaminantes y sedimentología en el Puerto de Huelva (río Odiel). Obra Pública, 30, 104-11 (in Spanish).

Periáñez, R., Abril, J. M. \& García-León, M. (1994d). Formulación y desarrollo de un modelo matemático de un sistema estuario. Aplicaciones. In Modelado de Sistemas en Oceanografía, Climatologia y Ciencias medioambientales, eds. A. Valle \& C. Parés. Imagraf, pp. 205-10 (in Spanish).

Periáñez, R., Abril, J. M. \& García-León, M. (1996). Modelling the dispersion of non-conservative radionuclides in tidal waters. Part 2: application to ${ }^{226} \mathrm{Ra}$ dispersion in an estuarine system. J. Environ. Radioactivity, 31(3).

Periáñez, R., Abril, J. M. \& García-León, M. (in press). Modelling the suspended matter distribution in an estuarine system. Application to the Odiel River in southwest Spain. Ecol. Modelling.

Prandle, D. (1974). A numerical model of the southern North Sea and the River Thames. IOS/R/4.

Prandle, D. (1984). A modelling study of the mixing of ${ }^{137} \mathrm{Cs}$ in the seas of the European continental shelf. Phil. Trans. R. Soc. Lon., A310, 407-36.

Pugh, D. T. (1987). Tides, Surges and Mean Sea Level. John Wiley, Chichester. Robertson, J. S. (1983). Compartmental Distribution of Radiotracers. CRC, Boca Raton, FL.

\section{APPENDIX}

\section{Hydrodynamic equations}

$$
\begin{aligned}
& \frac{\partial z}{\partial t}+\frac{\partial}{\partial x}[(D+z) u]+\frac{\partial}{\partial y}[(D+z) v]=0 \\
& \frac{\partial u}{\partial t}+v \frac{\partial u}{\partial y}+u \frac{\partial u}{\partial x}+g \frac{\partial z}{\partial x}-\Omega v+K \frac{u \sqrt{u^{2}+v^{2}}}{D+z} \\
& \quad-\frac{\rho_{\mathrm{a}}}{\rho_{\mathrm{w}}} \frac{C_{\mathrm{D}}}{D+z}|W| W \cos \theta=0 \\
& \frac{\partial v}{\partial t}+v \frac{\partial v}{\partial y}+u \frac{\partial v}{\partial x}+g \frac{\partial z}{\partial y}+\Omega u+K \frac{v \sqrt{u^{2}+v^{2}}}{D+z} \\
& \quad-\frac{\rho_{\mathrm{a}}}{\rho_{\mathrm{w}}} \frac{C_{\mathrm{D}}}{D+z}|W| W \operatorname{sen} \theta=0
\end{aligned}
$$

where $u$ and $v$ are the $x$ and $y$ components of the depth averaged water velocity, $z$ is the displacement of the water from the mean level $D, g$ is gravity, $\Omega$ is the Coriolis term, $K$ the bed friction coefficient, $\rho_{\mathrm{a}}$ and $\rho_{\mathrm{w}}$ are 
the air and water densities respectively, $C_{D}$ is a dimensionless drag coefficient, $W$ the air speed and $\theta$ the direction to which the wind blows measured anticlockwise from east.

$$
C_{\mathrm{D}}=(0.63+0.066 \mathrm{~W}) 10^{-3}
$$

Response to changes in atmospheric pressure:

$$
\Delta D=-\frac{\Delta P}{g \rho_{\mathrm{w}}}
$$

where $\Delta P$ is the pressure variation from the mean.

\section{Advective-diffusion equation}

$$
\frac{\partial C}{\partial t}+u \frac{\partial C}{\partial x}+v \frac{\partial C}{\partial y}=\frac{1}{H}\left[\frac{\partial}{\partial x}\left(H K_{u} \frac{\partial C}{\partial x}\right)+\frac{\partial}{\partial y}\left(H K_{v} \frac{\partial C}{\partial y}\right)\right]
$$

where $C$ is the concentration of the dissolved substance, $H=D+z$ is the instantaneous water level and $K_{u}$ and $K_{v}$ are the diffusion coefficients along the $x$ and $y$ directions.

\section{Suspended matter dynamics}

Deposition term:

$$
\frac{\partial m}{\partial t}=-\frac{v_{\mathrm{d}}}{H} m\left(1-\frac{|q|}{v_{\mathrm{cd}}}\right)
$$

$m$ is the suspended matter concentration $\left(\mathrm{mgl}^{-1}\right), v_{\mathrm{d}}$ is the deposition velocity, $v_{\text {cd }}$ is the critical deposition velocity and $|q|=\sqrt{u^{2}+v^{2}}$. Resuspension term:

$$
\frac{\partial m}{\partial t}=\frac{v_{\mathrm{r}} \rho_{\mathrm{m}} f}{H \rho_{\mathrm{w}}} 10^{6}\left(\frac{|q|}{v_{\mathrm{cr}}}-1\right)
$$

where $v_{\mathrm{r}}$ is the resuspension velocity and $v_{\mathrm{cr}}$ is the critical resuspension velocity. The dry weight fraction of small particles in the sediment, $f$ is fixed since the sedimentation rates are small (Periáñez et al., 1996) and therefore there will not be important changes in $f$ over timescale of some tidal cycles. In a similar way, bed consolidation is neglected. Flocculation processes are implicitly considered when a critical deposition velocity is introduced in the deposition term. 